\title{
Noble Gas Release from Bedded Rock Salt during Deformation
}

\author{
Stephen J. Bauer $\mathbb{D}^{1},{ }^{1}$ W. Payton Gardner, ${ }^{2}$ and Hyunwoo Lee $^{3}$ \\ ${ }^{1}$ Geothermal Research Department, MS 1033, Sandia National Laboratories, Albuquerque, NM 87185, USA \\ ${ }^{2}$ Department of Geosciences, University of Montana, Missoula, MT, USA \\ ${ }^{3}$ School of Earth and Environmental Sciences, Seoul National University, Seoul 08826, Republic of Korea \\ Correspondence should be addressed to Stephen J. Bauer; sjbauer@sandia.gov
}

Received 25 January 2019; Accepted 8 April 2019; Published 20 June 2019

Academic Editor: Henrik Drake

Copyright ( 2019 Stephen J. Bauer et al. This is an open access article distributed under the Creative Commons Attribution License, which permits unrestricted use, distribution, and reproduction in any medium, provided the original work is properly cited.

\begin{abstract}
Geogenic noble gases are contained in crustal rocks at inter- and intracrystalline sites. In this study, bedded rock salt from southern New Mexico was deformed in a variety of triaxial compression states while measuring the release of naturally contained helium and argon utilizing mass spectrometry. Noble gas release is empirically correlated to volumetric strain and acoustic emissions. At low confining pressures, rock salt deforms primarily by microfracturing, rupturing crystal grains, and releasing helium and argon with a large amount of acoustic emissions, both measured real-time. At higher confining pressure, microfracturing is reduced and the rock salt is presumed to deform more by intracrystalline flow, releasing less amounts of noble gases with fewer acoustic emissions. Our work implies that geogenic gas release during deformation may provide an additional signal which contains information on the type and amount of deformation occurring in a variety of earth systems.
\end{abstract}

\section{Introduction}

Noble gases present in crustal rocks are derived from groundwater (atmospheric origins), from magmatic activity (mantle origins), and from a variety of decay and nucleogenic reactions of natural radioactive elements (e.g., U, Th, and $\mathrm{K}$ ). Radiogenic noble gases are produced throughout the crust within mineral grains and retained to different degrees within the minerals depending upon the gas species, crystal structure, and the location and method of production. These gases migrate to the adjacent pore fluid and/or fracture networks over geological time periods via crystalline diffusion, decay recoil, and chemical dissolution [1]. Transport of gases occurs within the rock grain, along grain boundaries, in the pore fluid, and within the micro- to macrofracture network. Their release during natural and manmade stress and strain changes represents a signal of deformation (e.g., [2-6]).

Noble gas emission and its relationship to crustal processes have been studied for many years in the geologic community including correlations to tectonic velocities [7], origin of crustal fluids [8], qualitative estimates of deep permeability from surface measurements $[7,9]$, study of hydrothermal systems (e.g., [10]), and fingerprints of nuclear weapon detonation [11]. Increases in radiogenic gas at lab and field scales have been observed and related to preseismic stress, dilatancy, and/or fracturing of the rock and as potential precursory signals to earthquakes attributed to gas release due to preseismic stress $[2,3,12,13]$. Radon release has been observed relative to earthquake activity $[14,15]$. Postseismic anomalies of $\mathrm{He}$ isotopic composition have been observed in spring water [16]. Helium emission has been related to volcanic activity; for example, helium isotopes have been used to segregate helium release due to magmatic activity from crustal sourced (seismically released) helium $([17,18])$.

Laboratory studies have been used to determine, evaluate, and quantify gas release in conjunction with rock fracturing (e.g., $[19,20])$. These tests include gas analyses which are performed at infrequent intervals when deformation was halted either mid-test [20] or posttest after fracture [19]. Honda et al. [19] developed a relationship between deformation and ${ }^{40} \mathrm{Ar}$ release, and no relationship was evident for ${ }^{4} \mathrm{He}$. Radon emission during rock deformation has been studied in the laboratory for unconfined $[4,6]$ and confined conditions [5]. They collected $\mathrm{Rn}$ release data in stepwise load increments during laboratory deformation experiments and 
developed relationships between $\mathrm{Rn}$ release and deformation amount. Bauer et al. [2] demonstrated that release of radiogenic noble gases may be used as a new signal of rock deformation. Bauer et al. [3] show that the release of naturally occurring helium from micro-macrofracturing is a function of the systematic change in stress state by application of stresses sufficient to fracture the rock. However, the effect that changing the deformation type, from brittle fracturing to ductile flow, has on the release of geogenic gas from deforming rocks has never been investigated.

The geomechanics of rock salt have been widely studied to support high-level nuclear waste disposal, underground energy storage, and wellbore integrity in the Gulf Coast, (e.g., [21-23]). Rock salt will fracture at low confining pressures and temperatures, and sufficient differential stress and fracturing will readily give way to crystal plastic flow with increasing pressure and temperature [24]. At $30 \mathrm{C}$, [24] indicate the $5-6 \mathrm{MPa}$ confining pressure suppresses microfracturing. The ease in changing deformation styles with increasing confining pressure in rock salt lends itself to investigating the effect of the deformation style on noble gas release. Observations and quantification of plastic deformation mechanisms were not done in this study; rather, microfracturing was quantified as a proxy for brittle fracture and related to noble gas release.

The amount of gas liberated depends on the amount of gas in the rock and that made accessible during deformation [3]. Gas is released during deformation due to the creation of new fracture surfaces, comminution of mineral grains, and liberation of gas stored along grain boundaries.

In this study, we perform a laboratory-based investigation of noble gas release for a variety of deformation styles through laboratory triaxial experiments performed upon a bedded rock salt. We develop empirical relationships of specimen stress and strain, microstructural evolution, and acoustic emissions to noble gas release. We make continuous measurements of noble gas $\left({ }^{4} \mathrm{He}\right.$ and $\left.{ }^{40} \mathrm{Ar}\right)$ release at confining pressures to $69 \mathrm{MPa}$, thus better simulating a variety of environmental conditions in the crust. Our study provides a unique data set to analyze deformation and gas release with high temporal resolution and the effect of deformation style on geogenic gas release.

\section{Materials and Methods}

Rock salt used in this study was obtained from the Waste Isolation Pilot Plant (WIPP) in southeastern New Mexico. It is from the bedded salt horizon of the Permian Salado formation; the formation and brines are on the order of $200 \mathrm{Ma}$ years old $[25,26]$. X-ray diffraction analysis shows up to $5 \%$ water-soluble and water-insoluble impurities, including quartz, gypsum, and clays, consistent with previous studies [26]. WIPP salt has been shown to contain on the order of $0.5-0.6 \%$ by weight water [27]. The gas composition has not been specifically evaluated; however, gas chemistry was determined in a $3 \mathrm{~m}$ thick unit about $20 \mathrm{~m}$ below the level used here [28] and considered representative. Brine in fluid inclusions is enriched in both ${ }^{40} \mathrm{Ar}$ and ${ }^{4} \mathrm{He}$ relative to the atmosphere (0.934 mole \%, 0.000524 mole $\%$, respectively), and helium is enriched by a factor of 250, compared to the atmospheric abundance [28]. The likely source of excess ${ }^{4} \mathrm{He}$ is alpha decay of naturally occurring radioactive elements; argon comes from the decay of ${ }^{40} \mathrm{~K}$ [28].

The brine resides primarily within intragranular fluid inclusions, at grain boundaries in pores and tubules. Some of the clay minerals in the rock salt may also contain brine. Gases which are pertinent to this study are associated with brine, either dissolved or in the form of secondary-phase gas bubbles. Fluid inclusions are found along healed grain boundaries as pores and tubules and within intragranular pores of cubic habit (Figure 1). Microfracture of grains and along grain boundaries can directly release secondary-phase gases. In addition, the dissolved gases in the brine may also be important, as dissolved gas will be liberated from the solution during deformation and subsequent fluid pressure release. Deformation of fluid-filled intragranular pores in rock salt has been postulated to decrease its strength due to locally high pore pressures [29, 30].

Sample preparation and assembly is like that of Bauer et al. [3] with exceptions noted (Figure 2). Rock cores were taken parallel to bedding twenty years ago and carefully stored (the rock had the potential to relax). Their identification locates them in time and space. Rock samples are right circular cylinders, nominally $9.3 \mathrm{~cm}$ in diameter and $19-20 \mathrm{~cm}$ in length, prepared to ASTM tolerances and oven-dried for a week at $40^{\circ} \mathrm{C}$. Lateral displacements were measured with displacement transducers (LVDTs) attached to brass buttons on the sample along a diameter near midheight. Axial LVDTs were affixed to the sample end caps (Figure 2). LVDT displacements are averaged to calculate strain. Samples were sandwiched at the top and bottom between alternating layers of pressed metal fiber mesh and steel spacers to assure gas flow accessibility to the core ends. The sample is then jacketed with a thin layer of UV-cure urethane. This layer adheres tightly to the rock surface inhibiting gas flow along the rock surface. A sleeve of polyolefin shrink tube is placed over the first layer of UV cure urethane and is then encapsulated in another two layers of UV-cure urethane. Stress is calculated using the measured force and updated cross-sectional area based on lateral displacements.

The mechanical portion of the test system consists of a triaxial cell in a $4.45 \mathrm{MN}$ loading frame [3]. In this work, a pressure vessel with a large internal diameter was utilized. The internal diameter of the pressure vessel is $\sim 18 \mathrm{~cm}$ to contain the large sample diameter along with internal displacement and acoustic emission transducers mounted on the outside of the sample. The mechanical test system has a pore-fluid flow-through capability used with high pressure (to simulate pore pressure at depth) and low pressure (in the present application of high vacuum). The vacuum pressures achieved required specific adaptors to connect vacuum lines of the analytical devices to high-pressure lines of the triaxial test system, accessing the top and bottom of the specimen (Figure 2). The test system data acquisition and controls were computer-driven using MTS $^{\text {тм }}$ hardware and software; the tests are conducted in displacement control.

The residual gas analysis portion of the test system utilizes mass spectrometry, which measures the mass-to- 


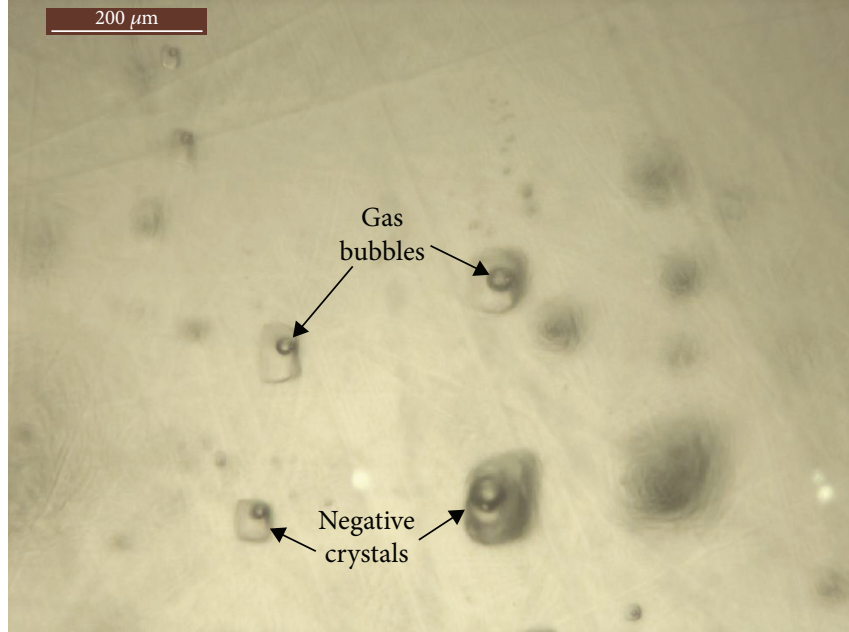

(a)

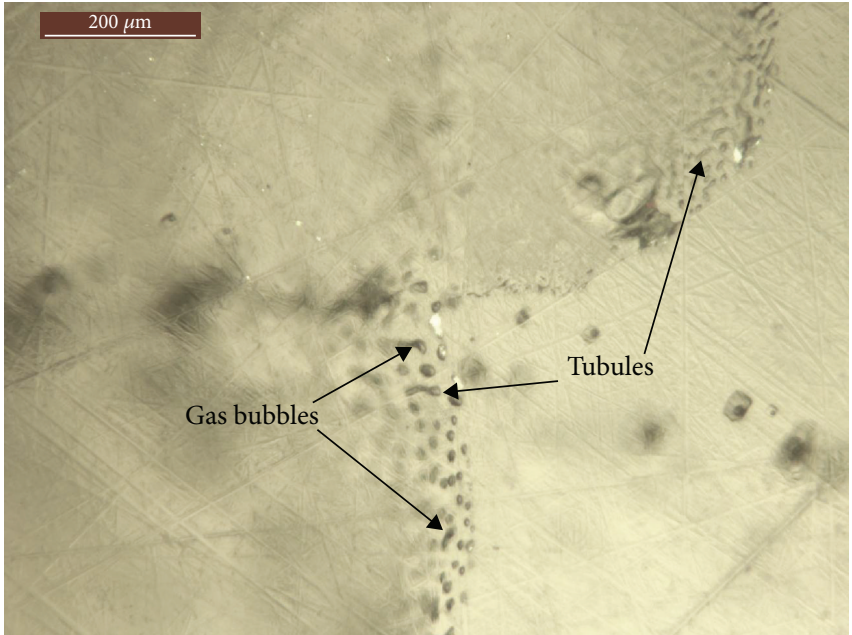

(b)

FIGURE 1: Gas in bubbles in undeformed WIPP salt; (a) intragranular fluid inclusions and (b) along healed grain boundaries, transmitted light.

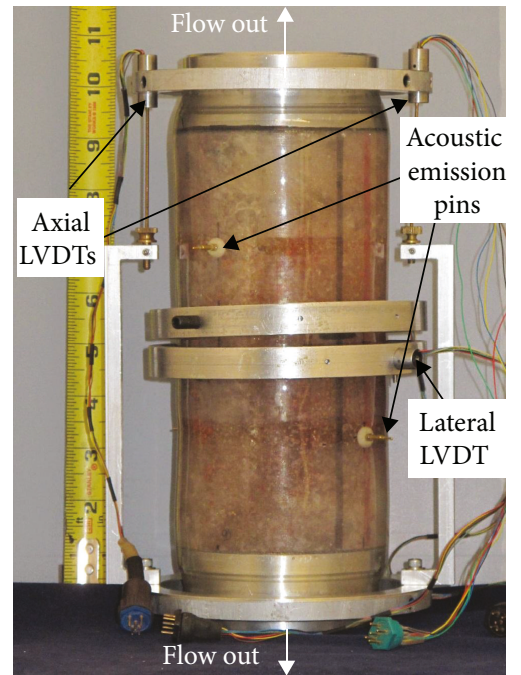

Figure 2: Typical sample assembly showing locations of LVDTs, acoustic emission pins, and noble gas flow ports.

charge ratio abundance of gas-phase ions. Two different mass spectrometers were used: a helium leak detector (LD) which measures the flow rate of mass 4 and a quadrupole mass spectrometer (QMS) capable of scanning the gas composition over a broad mass range. The helium LD, an Oerlikon Leibold Phoenix L300i, is a specialized mass spectrometer which we use to detect only ${ }^{4} \mathrm{He}$. It works in the mass range of 2,3 , $4 \mathrm{amu}$, with a minimum detectable leak rate in vacuum mode of $<5 \times 10^{-12} \mathrm{mbar} 1 / \mathrm{s}$; the vacuum runs at about $10^{-3} \mathrm{mbar}$. The time constant of the leak rate signal is $<1 \mathrm{~s}$, and the filament is iridium/yttrium oxide. The QMS is a Pfeiffer HiQuad $^{\mathrm{TM}}$, which can analyze for neutral particles with a mass range from 1 to $340 \mathrm{amu}$. The mass spectrometer continually scans for gases during the deformation. The scan speed is variable, with a dwell time between $0.125 \mathrm{~ms}$ and 60 s/amu; typically, a full scan time for a suite of gases (10 species) is on the order of 1-2 seconds. The analyzer is a
QMA 410, with a cross beam ion source and a detection limit at $1 \times 10^{-15}$ mbar. The detector is a SEM 217/Faraday, and the filament is tungsten. The maximum operating pressures are Faraday $10^{-4} \mathrm{mbar}$ and SEM $10^{-5} \mathrm{mbar}$. For these measurements, an acetone/ $\mathrm{CO}_{2}$ trap is in line with the flowing gases to protect the vacuum line. The software which is used to operate the HiQuad ${ }^{\mathrm{TM}}$ is Quadera $^{\circledR}$, with a LabVIEW ${ }^{\circledR}$ based user interface for data acquisition and control. For both types of gas measurements, a liquid nitrogen trap is in line with the flowing gases to protect the vacuum line, along with low-pressure relief valves. The helium leak detector recorded the ${ }^{4} \mathrm{He}$ release rate during the deformation as a volume flow rate and is displayed as flow rate versus time. The QMS was used to observe changes in gas composition, and the ${ }^{4} \mathrm{He}$ and ${ }^{40} \mathrm{Ar}$ mixing fractions in parts per million (ppm) are presented as a function of time. Given the low vacuum pressure and the pump rate of the turbo pumps 
TABLE 1: Triaxial test matrix and gas release measurements.

\begin{tabular}{lcccccc}
\hline Sample ID & Test ID & $\begin{array}{c}\text { Confining pressure } \\
(\mathrm{MPa})\end{array}$ & $\begin{array}{c}\text { Gas measurement } \\
\text { instrument }\end{array}$ & $\begin{array}{c}\text { Maximum axial } \\
\text { strain }\end{array}$ & $\begin{array}{c}\text { Cumulative helium } \\
\text { release }(\mathrm{cc})\end{array}$ & $\begin{array}{c}\text { Microfractures per } \\
\mathrm{cm}\end{array}$ \\
\hline QGU16-3_6.0 & A & 6.9 & Helium LD & 0.0120 & 0.000054 & $\mathrm{n} / \mathrm{a}$ \\
QGU16-4_8.0 & B & 6.9 & QMS & 0.0250 & 0.9 & $\mathrm{n} / \mathrm{a}$ \\
QGU16-3_6.5 & C & 34.5 & Helium LD & 0.0244 & 0.0000011 & 8.4 \\
QGU16-3_6.5 & D & 3.45 & Helium LD & 0.0264 & 0.0185 & 26.7 \\
QGU30-1_0.5 & E & 13.8 & Helium LD & 0.028 & 0.0000074 & 10.2 \\
QGU30-1_0.5 & F & 69.0 & Helium LD & 0.023 & 0.0000022 & $\mathrm{n} / \mathrm{a}$ \\
\hline
\end{tabular}

maintaining the vacuum, the noble gas molecules travel near the speed of sound from the rock sample to the sensor; thus, the gas flow measurements are nearly instantaneous.

We present results from six triaxial experiments performed on four specimens of bedded salt, one experiment using the QMS to investigate gas composition, and five experiments using the helium leak detector to quantify gas release (Table 1). The value of salt specimen reuse for multiple tests has been demonstrated as it removes sample-to-sample variability, and its effect on strength and ductility has been evaluated (e.g., [24, 31-33]). In this study, we reuse samples because of low availability of the rock salt, and to demonstrate helium release from the same rock at different stress conditions results in different amounts of microfracturing.

2.1. Experimental Setup. The experimental setup and test methods used in this study are similar to those used in Bauer [34]. The acoustic emission (AE) system used here is a passive sampling system, meaning that it only detects events naturally occurring within the specimen. Piezoelectric event arrival pins sense the $\mathrm{p}$-wave and convert it to an analog electrical signal to be recorded after further processing by the rest of the AE system. Four acoustic emission transducers were attached to the sample at quarter perimeters. An additional four to eight acoustic emission pins would have been required to locate $\mathrm{AE}$ events. Once an event occurs within the specimen, the AE system amplifies it through a $60 \mathrm{db}$ amplifier, bringing the signal up to the 20 to $50 \mathrm{mV}$ range. This higher voltage range makes it easier to discriminate the events and subsequently record the event with the highspeed digitizers (capable of sampling at $40 \mathrm{MHz}$ ) attached to a nearby computer. The discriminator compares signals on multiple pins to determine whether an event occurred; acoustic emission events are counted if similar magnitude and shape signals are triggered in at least three of the four transducers within a specified time window. The electrical output from events accumulates as voltage(s); $1 \mathrm{~V}$ corresponds to $1000 \mathrm{AE}$ events.

Jacketed and instrumented specimens were placed onto the base of the pressure vessel and connected to porepressure feed-throughs in the pressure vessel. The pressure vessel was then assembled and placed into the reaction frame. The actuator in the base of the frame was raised gradually to bring the pressure vessel piston into contact with the reaction frame. The pressure vessel was then connected to the pressure intensifier and filled with Isopar ${ }^{\circledR}$. The sample was then subjected to 1-2 MPa confining pressure and the vacuum pumping system applied to the core ends through the pore pressure ports. The sample was first vacuum-pumped at low confining pressure to bring the pore pressure system under vacuum. The test confining pressure was then applied and held for another 24 hours while the specimen was continuously pumped by the vacuum system. This was done to remove accessible gases and water from accessible crack and grain boundary surfaces.

During the experiment, confining pressure is controlled, measured, and tracked using a pressure transducer located in the intensifier connection line about a meter from the pressure vessel. Axial force is measured with a load cell external to the pressure vessel, and O-ring friction is corrected during data analysis. The specimens are deformed using a controlled displacement mode and shortened at a rate of approximately $5 \times 10^{-6} \mathrm{~s}^{-1}$. Force, displacement, acoustic emissions, confining pressure, and real-time gas flow or gas composition were recorded in an automatic data acquisition/control system as a function of time.

Six triaxial tests were completed, sample QGU16-3_6.5 was tested at 69.0 and $13.8 \mathrm{MPa}$ confining pressure, and sample QGU30-1_0.5 was used to test at 34.5 and $3.45 \mathrm{MPa}$ confining pressure. Two tests were run at $6.9 \mathrm{MPa}$ confining pressure; one used the helium leak detector, and the other used the quadrupole to sense gas release. All tests were conducted at ambient laboratory temperature.

\section{Experimental Results}

The information collected during the triaxial constant strain rate versus time experiments is displayed in Figure 3. The samples are initially subjected to confining pressure and then subjected to triaxial deformation while recording force, displacement, acoustic emissions, and gas release. Strains, acoustic emissions, and real-time gas released are plotted against elapsed time for the triaxial segment of the test (Figure 3). For all experiments, axial strain increases (shortening) and lateral strain decreases (expansion) during loading. Upon unloading, the strains are near constant indicating that most of the deformation is permanent. We use the convention that compressive stresses and compactive strains are positive. The magnitude of the axial strain for all tests was intended to be on the order of 0.025 . Test A was terminated prematurely due to experiment complications. All tests record AEs and gas release (flow rate or composition) and 


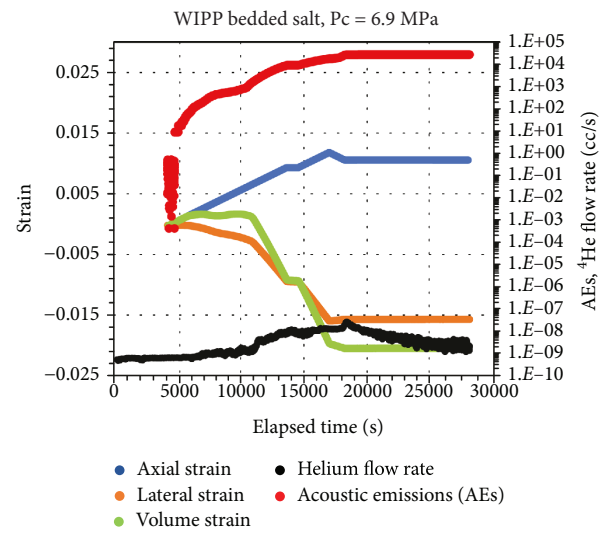

(a)

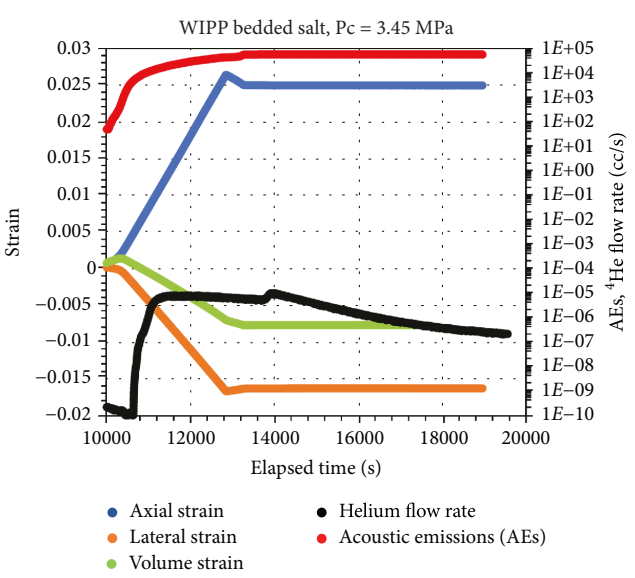

(c)

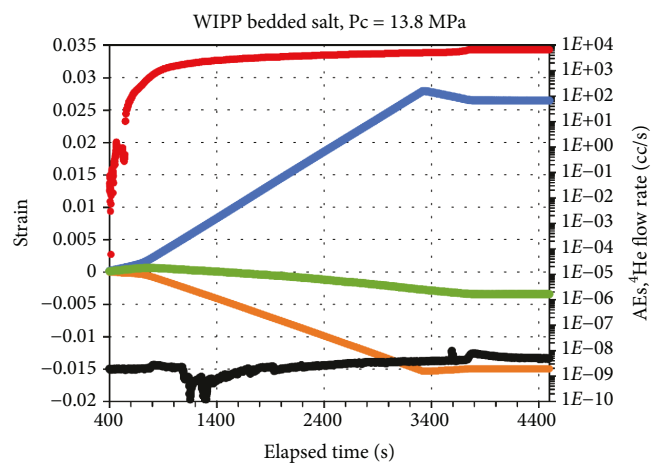

$\begin{array}{ll}\text { - Axial strain } & \text { - Helium flow rate } \\ \text { - Lateral strain } & \text { - Acoustic emissions (AEs) } \\ \text { - Volume strain } & \end{array}$

(e)

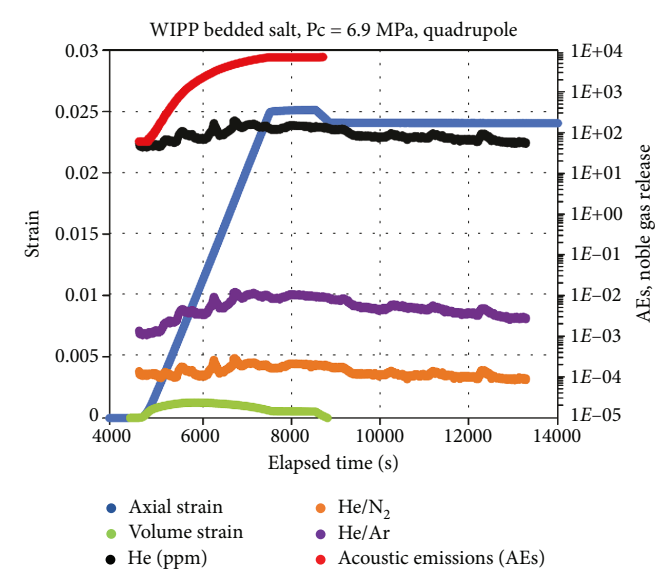

(b)

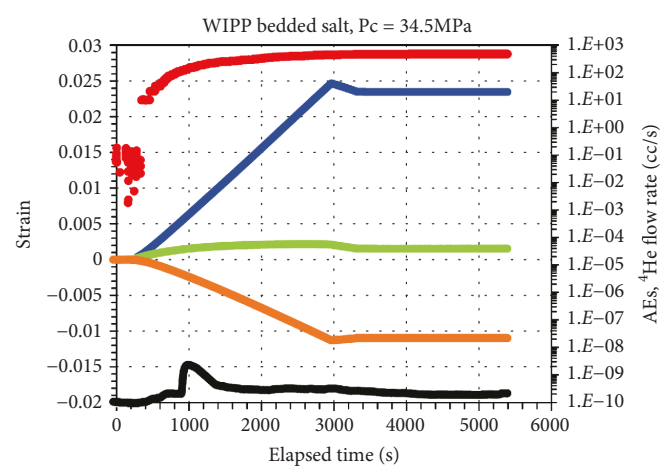

- Axial strain - Helium flow rate

- Lateral strain

- Acoustic emissions (AEs)

(d)

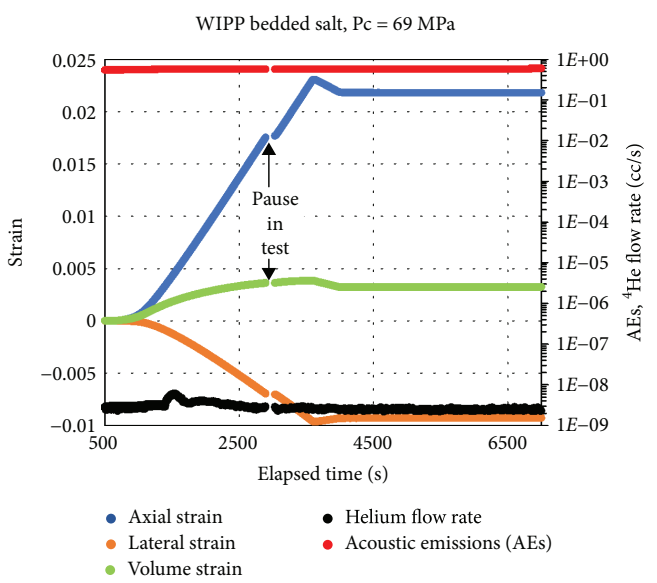

(f)

Figure 3: Strains, cumulative acoustic emissions, and gas release (helium flow; ccSTP/s) rate or gas concentration (ppm) versus time. (a) Sample QGU16-3_6.0, Pc=6.9 MPa; (b) sample QGU16-4_8.0, Pc=6.9 MPa; (c) sample QGU16-3_6.5, Pc=3.45 MPa; (d) sample QGU16-3_6.5, Pc = 34.5 MPa; (e) sample QGU30-1_0.5; Pc = 13.8; (f) sample QGU30-1_0.5, Pc =69.0 MPa.

the number of AEs. Gas release generally increases with decreasing confining pressure. Gas release is sometimes episodic during axial loading. For test $\mathrm{D},{ }^{4} \mathrm{He}$, and ${ }^{4} \mathrm{He} / \mathrm{N}_{2}$, ${ }^{4} \mathrm{He} / \mathrm{Ar}$ ratios are presented. Acoustic emissions start early in the loading (about 0.25 of yield stress) and progressively increase during loading. AEs stop once loading stops, and gas release decreases with time after loading stops. Generally, gas release decreases to background levels within an hour of unloading. The area under the flow rate versus time curve represents the amount of helium released in cc.

For the six triaxial experiments, cumulative gas release during the loading portion of the test is given in Table 1; most tests were run to about $2.5 \%$ axial strain resulting in differing amounts of volumetric strain. To calculate the 


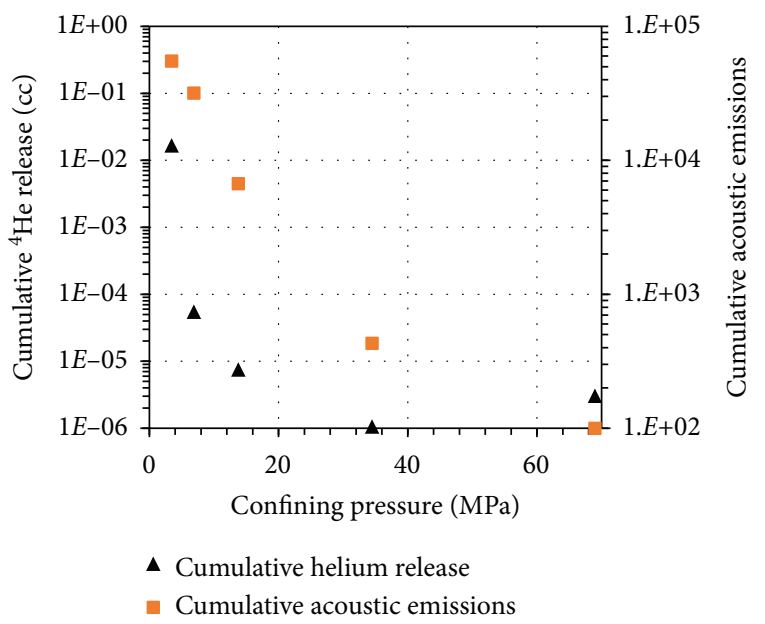

Figure 4: Cumulative helium release and acoustic emissions versus confining pressure.

amount of helium released during the test, we integrate the instantaneous helium release over the deformation time. Helium release and acoustic emissions generally increase with decreasing confining pressure (Figure 4). In each case of sample reuse, the sample was tested initially at the greater confining pressure, 34.5 and $70 \mathrm{MPa}$. In both high-pressure tests, a relatively small amount of helium was released, and the same samples released significant amounts of helium when tested at a low confining pressure. An inverse relationship between confining pressure and cumulative helium released and acoustic emission counts is obtained (Figure 4). As well, there appears to be a direct relationship between the volume of gas released and acoustic emissions.

Stress/strain behavior and helium release for the triaxial experiments is shown in Figure 5. In the 5A test, the displacement gauges were problematic, so the strain data is not as reliable as that for the other five tests. Each sample was subjected to approximately the same amount of axial strain. For the confining pressure range explored, the stress strain response of the salt is similar with slight differences noted. At the greatest confining pressure, tests $\mathrm{D}$ and $\mathrm{F}$ show slight compaction and border on isochoric. For both these tests, small bursts of gas are observed early in the loading, which we attribute to sample end-effect localized deformation. Samples tested at lower pressure yield and then work harden; samples pretested at high confining pressure appear stiffer for their initial loading than do other samples. All samples tested at $13.8 \mathrm{MPa}$ and lower pressures show evidence of dilation (change from compaction to expansion in volumetric strain).

While the stress strain curves appear smooth, the gas release response is episodic for some tests. The helium flow rate scale is different for some tests to show more detail in gas flow. Tests A and B were run at the same confining pressure; the difference between the two tests is the gas analysis methodology. Both samples displayed significant release of helium during deformation; there was no specimen failure or macrofracture, but gas release tended to increase during the deformation of each sample. Using the QMS to scan over a variety of gases (test B), helium shows the strongest signal. $\mathrm{N}_{2}$ and Ar concentrations in the brine are not significantly increased over atmospheric ratios, thus release of the geogenic gases does not produce a large signal over the background concentrations. In contrast, helium is several orders of magnitude higher in the fluid inclusions, thus releasing even a small amount of geogenic gas causing a large increase in the helium concentration above the residual background. Tests $\mathrm{D}$ and $\mathrm{F}$, run at 34.5 and $69 \mathrm{MPa}$ confining pressure, respectively, showed only a small amount of gas release during deformation. Test $\mathrm{C}$, the lowest confining pressure test, released the most helium and experienced the greatest flow rate of helium.

Cumulative helium release is plotted versus volumetric strain in Figure 6. The helium flow rate increases with increasing volumetric strain for all samples. Helium flow rates increase with decreasing confining pressure; total helium release increases with decreasing confining pressure.

Compaction and dilatant response of the samples to imposed deformation coupled with flow rate and total helium release are shown in Figure 6. Increases in volumetric strain are considered compaction, whereas reversals to decreases are considered dilation. Helium is released during the compaction for all sample phases to different degrees. An increase in helium release flow rates is observed as samples transition from compaction to dilation for tests $\mathrm{A}$, $\mathrm{B}, \mathrm{C}$, and D. Greater helium release rates are observed during the dilation phase of the deformation for tests A, B, and C, indicating cracking to release helium and an increase in flow paths. This observation is magnified in the inset of Figure 6(c) for improved visualization. In test $A$, there is an increase in cumulative helium release at -0.009 volumetric strain; at this time during the test, axial loading was paused as the intensifier was reprimed. Tests D and F exhibit a much smaller gas release signal than the lower confining pressure tests do. In tests D and F, the large jump in helium flow observed early in the test may be the consequence of a small amount of fracturing near the sample end (an end effect).

\section{Observations}

All samples were ultimately deformed at $13.8 \mathrm{MPa}$ confining pressure or lower since the high confining pressure samples 


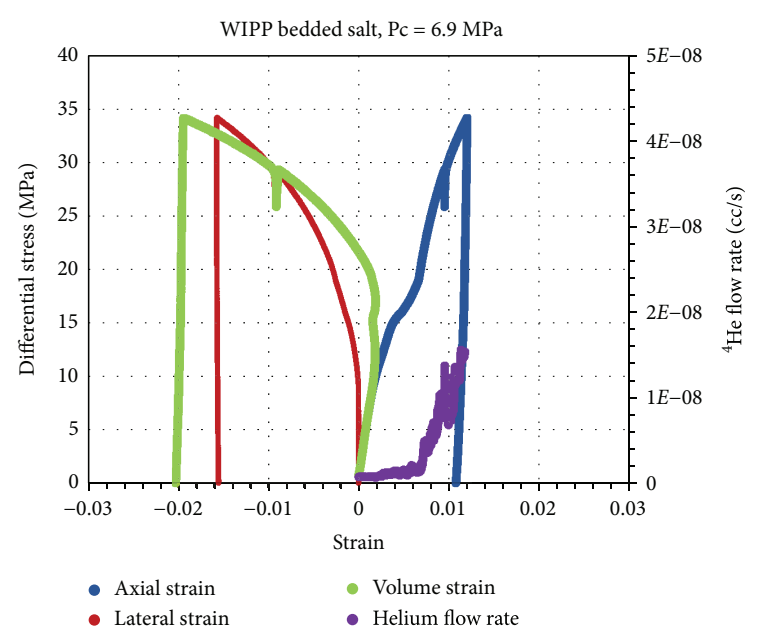

(a)

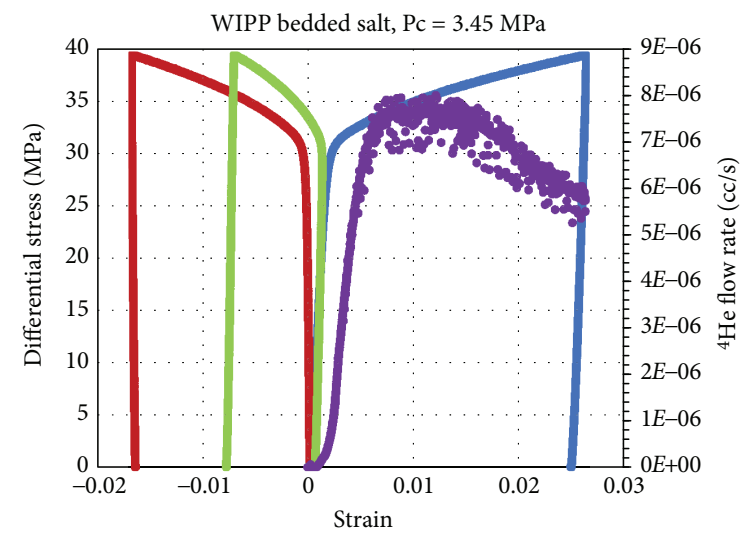

- Axial strain

- Volume strain

- Lateral strain

(c)

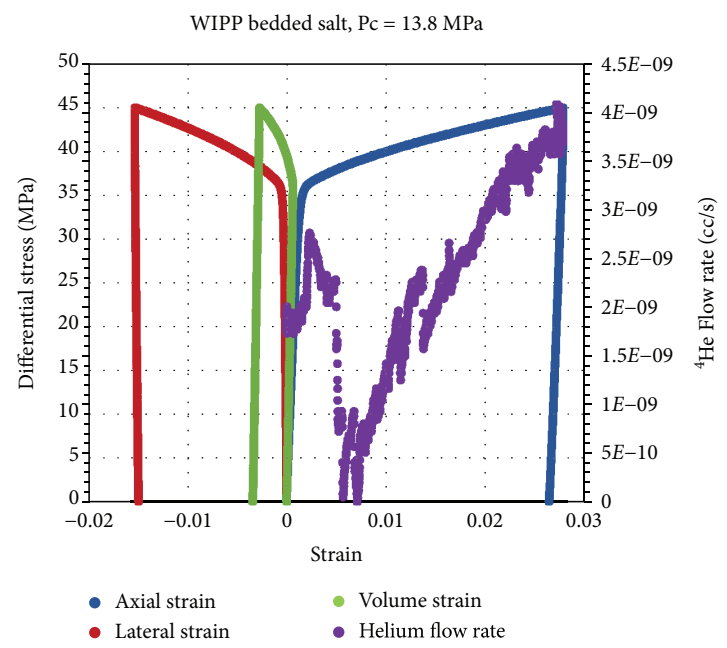

(e)

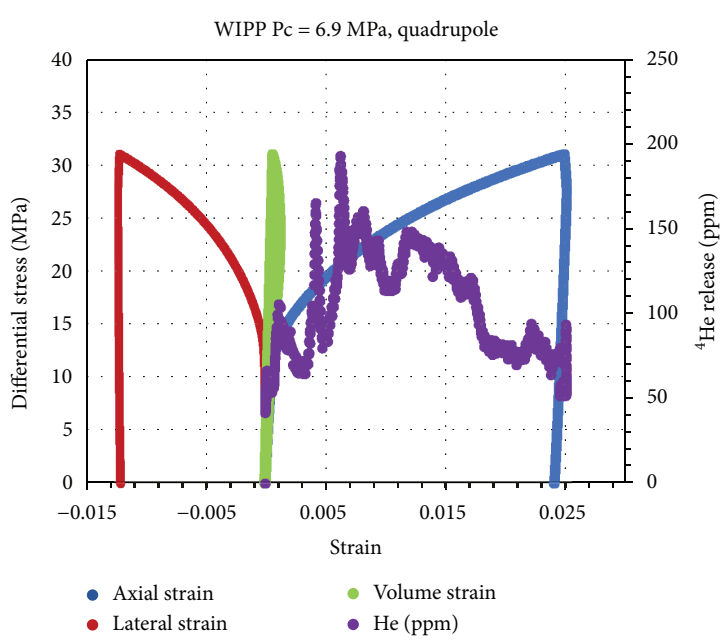

(b)

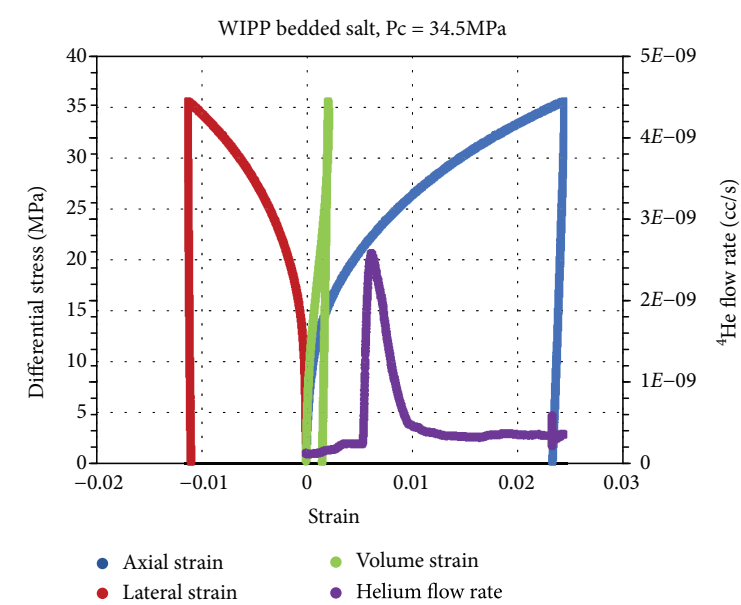

(d)

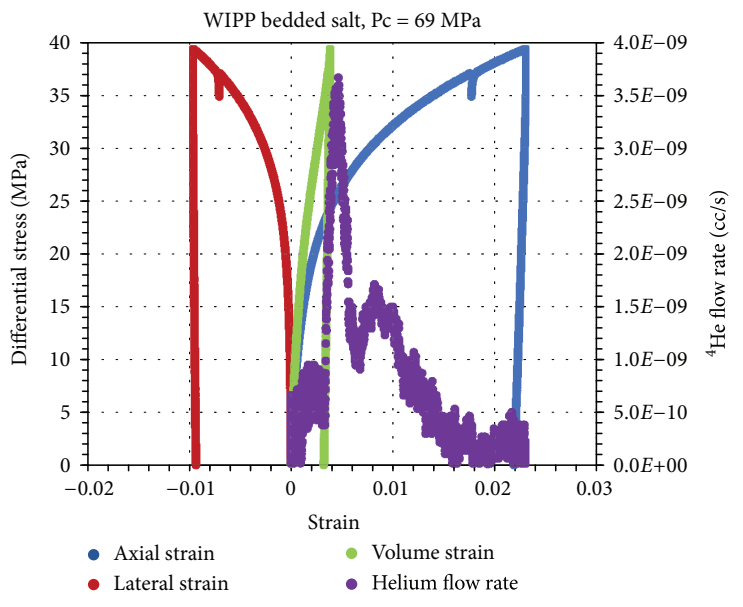

(f)

Figure 5: Differential stress versus strain and helium flow rate (a, c, d, e, f) and helium release (b) versus axial strain.

were retested at a lower confining pressure. Microfracturing was the deformation mechanism evaluated in all samples. To investigate the degree and type of fracturing, deformed samples were cut dry along a diameter to expose a cross section of the sample with a diamond impregnated wire saw, impregnated with a low viscosity blue stained epoxy, and successively polished and viewed in transmitted and reflected light. The epoxy accessed and filled interconnected cracks and pores. 


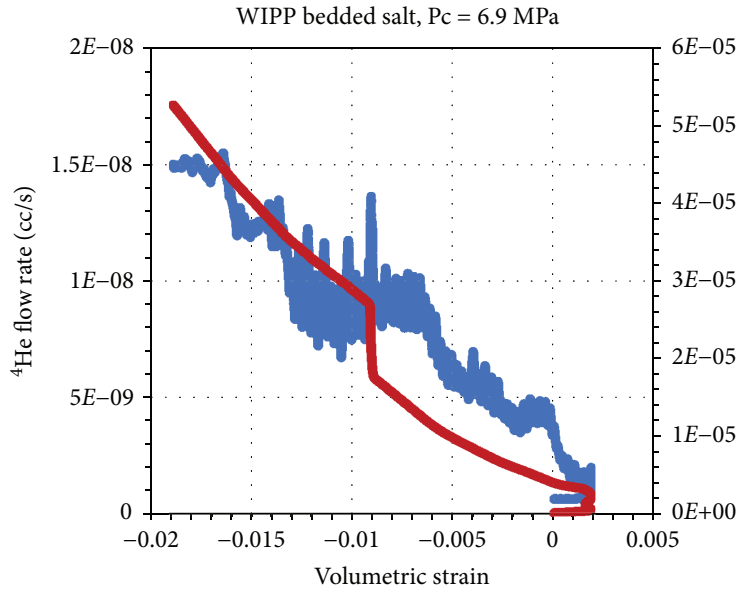

(a)

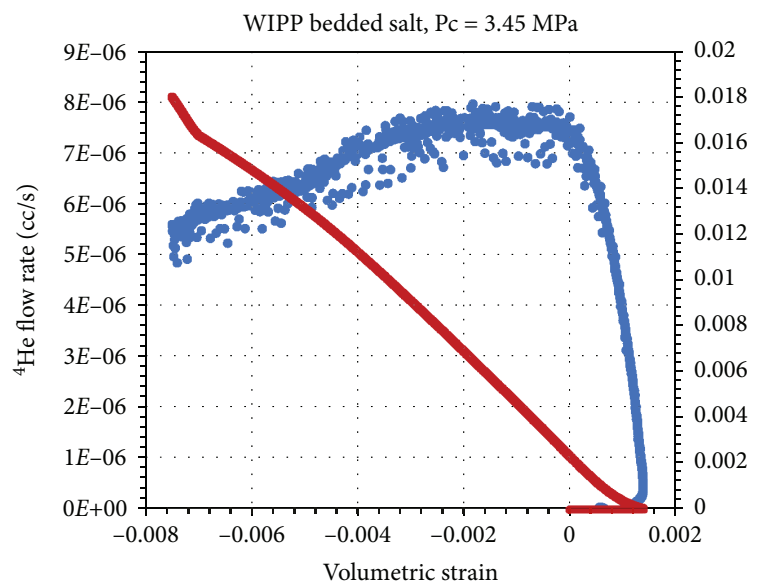

(c)

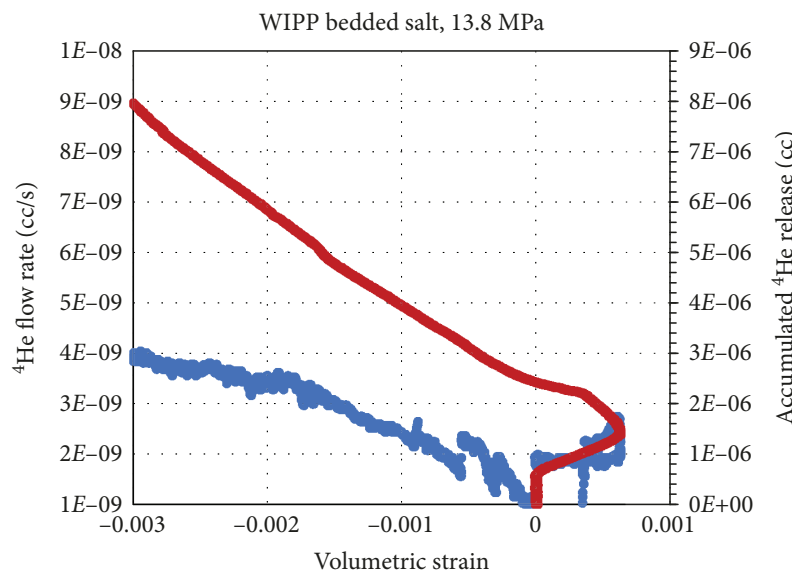

(e)

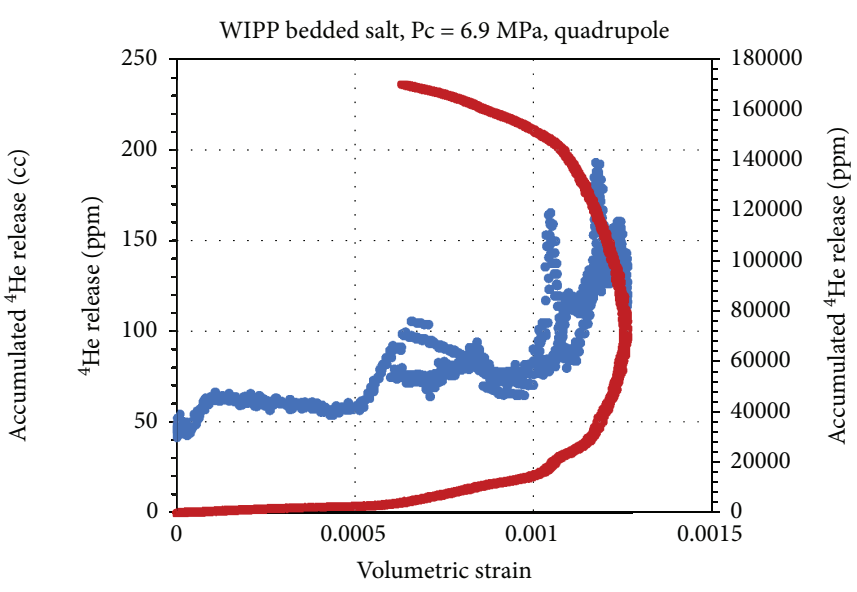

(b)

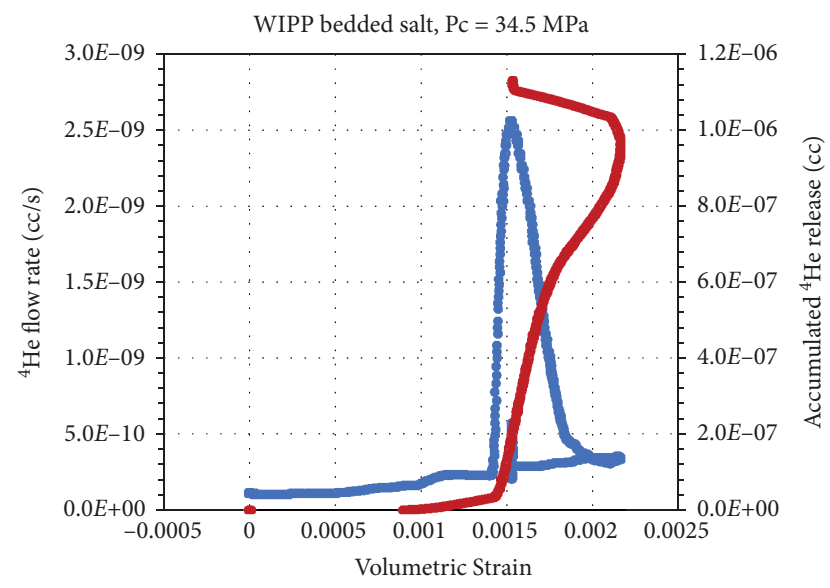

(d)

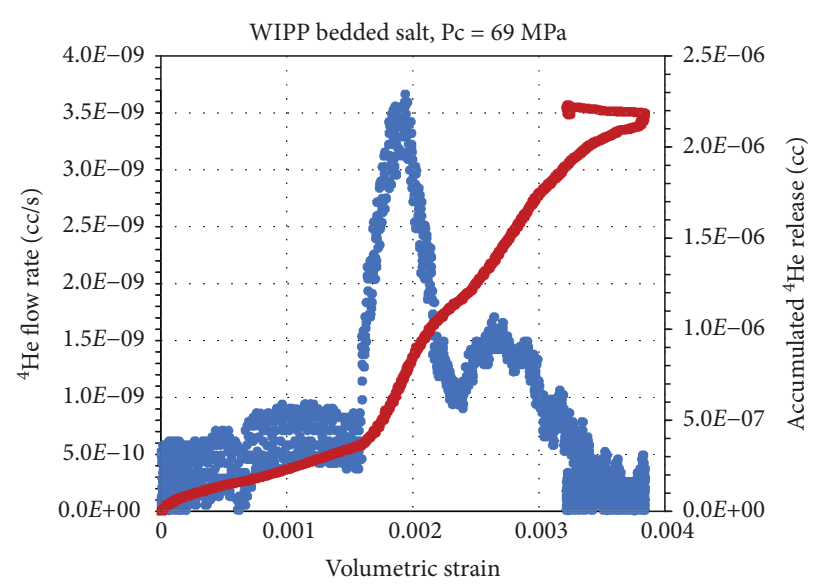

(f)

Figure 6: Helium flow rate (blue: a c, d, e, and f), helium release (blue: b), and accumulated helium release (red) versus volumetric strain.

Inter- and intragranular microfracturing is exhibited in all samples. Intragranular fractures tend to follow cleavage, and their intersection with gas-bearing fluid inclusions may release gas (Figure 7). Intergranular fracture open grain boundaries, releasing gas contained from tubules and pores, here filled with blue-stained epoxy.

We counted the microfracture filled with blue-stained epoxy by traversing $100 \mathrm{~cm}$ in an orthogonal grid, parallel and perpendicular to the loading direction. The results are expressed the linear crack density (LCD), and the number of microfractures per centimeter traversed (Table 1 and Figure 8). We observe that the LCD increases with decreasing confining pressure and the LCD increases with increasing cumulative helium released. Also, the cumulative acoustic emissions increase with increasing cumulative helium released. 


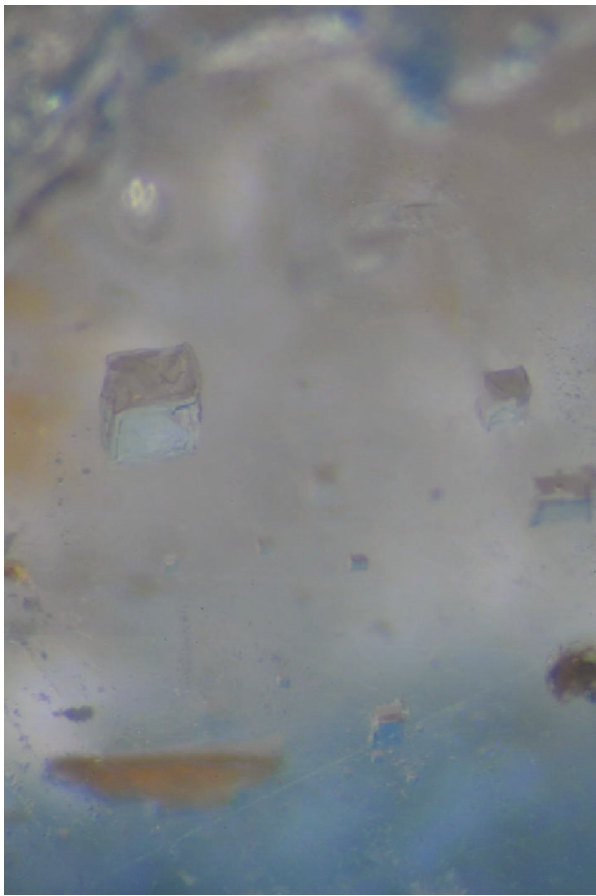

(a)

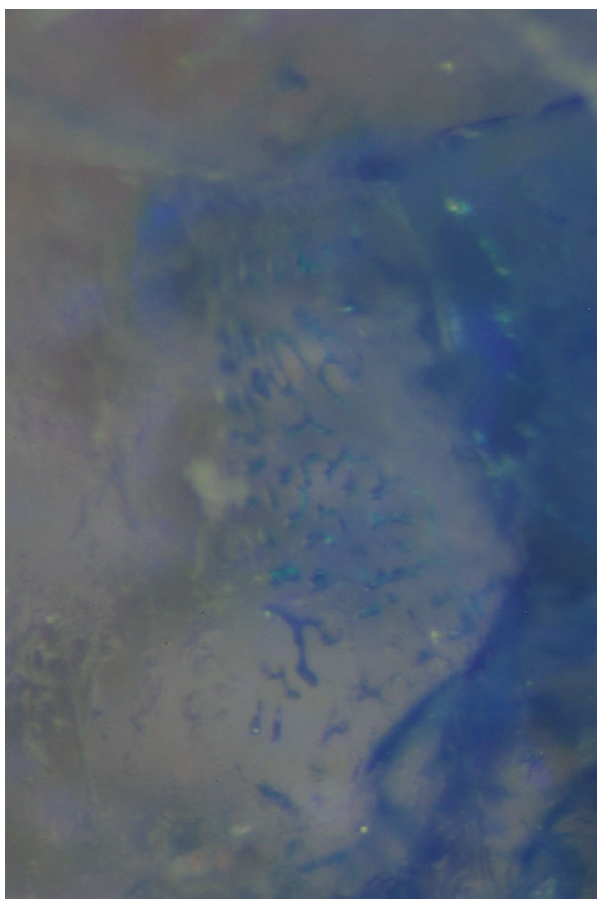

(c)

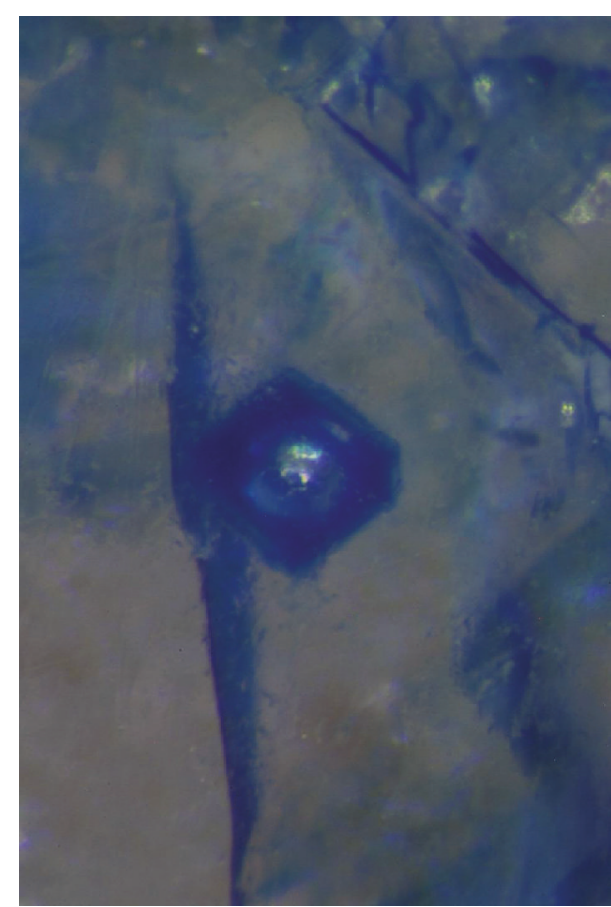

(b)

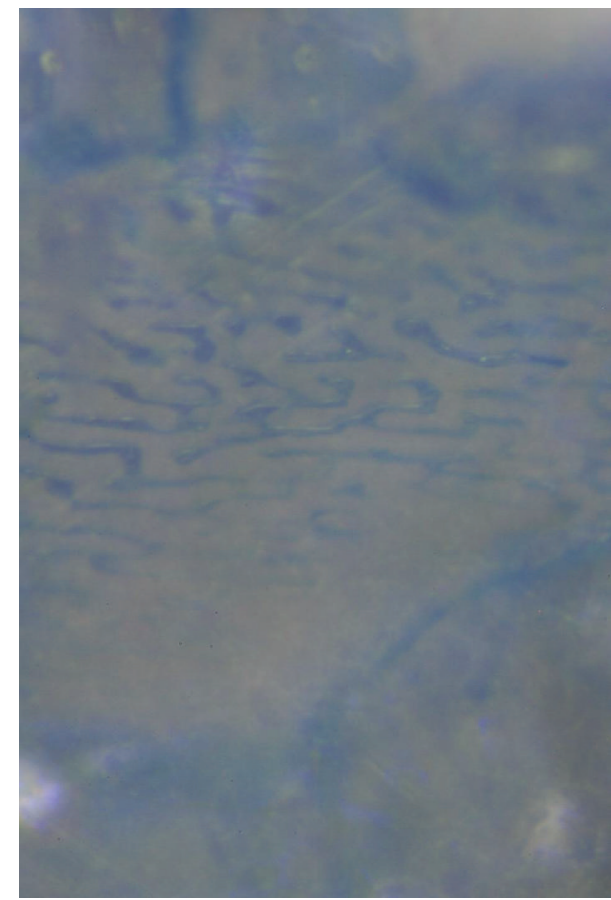

(d)

FIgURE 7: All images are of deformed sample QGU16-3_6.0. (a) Fluid inclusions not intersected by fractures in deformed salt. (b) Intragranular fracture intersecting a fluid inclusion. (c, d) Intergranular fracture along the grain boundary with blue-stained epoxy-filled tubules (reflected light, vertical field of view is $2.25 \mathrm{~mm}$ for each image).

\section{Discussion and Conclusions}

These data provide information on the mechanics and timing of gas release. Previous studies have shown that helium is released during elasticity and brittle deformation from both sedimentary and crystalline rocks $[2,3,35]$. In this study, we show that helium and argon are released from rock salt during mechanical deformation. Most testing focused on helium and its release signal changes as a function of confining pressure. We observe decreases in helium released, acoustic emissions, and microcrack densities with increasing confining pressure. 


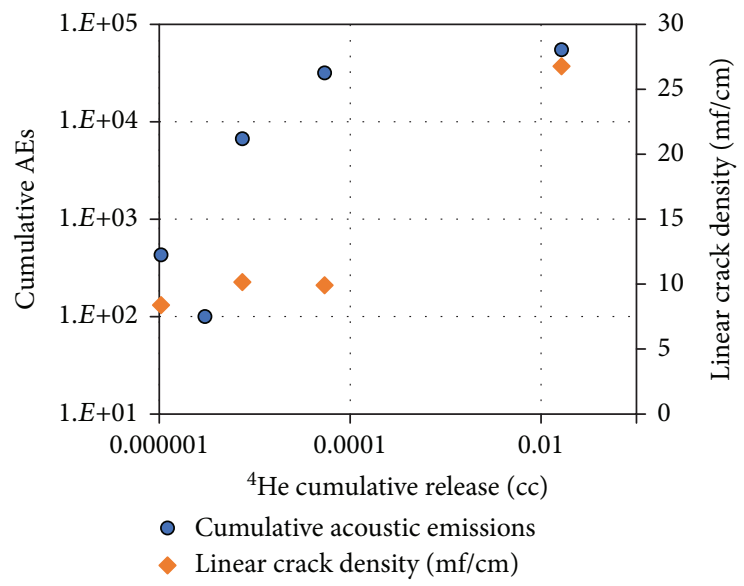

Figure 8: Cumulative helium release plotted versus cumulative acoustic emissions and linear crack density.

The data show an apparent cause-and-effect relationship between the accumulation of strain and noble gas release. Results from the laboratory and observational work presented include the following: (1) noble gases are released and measured real-time during triaxial deformation of bedded rock salt; (2) at low confining pressures $(<6.9 \mathrm{MPa})$, the noble gas release signal begins early in the loading $(<1 / 3$ of yield) and continues during axial loading; (3) the noble gas released depends on initial gas content, pore structure, and its evolution during deformation, deformation amount, and permeability; (4) the noble gas release rate increases as strain and microfracturing increase; (5) the noble gas release rate increases with decreasing confining pressure; (6) gases are released from inter- and intracrystalline sites as evidenced by intra- and intergranular microfractures; and (7) there appears to be a direct relationship between helium release and acoustic emissions.

These results add to the observations on the effects of mechanical stress and deformation on the release of accumulated radiogenic noble gases in rock, by considering the style of deformation on the amount of gas release. The release of radiogenic noble gases from deforming rock salt has a systematic stress and confining pressure-dependent pattern. At low confining pressure, microfracturing is signaled by observable acoustic emissions and plentiful noble gas release. Microfracturing gives way to presumed intracrystalline plasticity flow at higher confining pressure, characterized by intracrystalline-dominated strain, less microfracturing, less acoustic emissions, and lower noble gas release.

Kennedy and van Soest [7] relate tectonic deformation processes at the continental scale to helium concentration and isotopic composition in subsurface fluids and discuss deep permeability. The existence of deep permeability implies pressure-driven flow through cracks and fractures. The creation of cracks and fractures provides a source mechanism for noble gas release. [16] attributed helium isotope variations in groundwater in conjunction with seismic activity to mechanical processes (brittle deformation). Helium degassing has been shown to increase prior to volcanic eruptions, and its release has been delineated between volcanic and earthquake-related processes [17]. Accumulated crustal helium is released due to volcanic activity over geologic timescales [18]. Extension of the laboratory results to earthen processes has a broad implication that the brittle ductile transition would demark a boundary, above which brittle fracture would provide a source mechanism for noble gas release. Below this transition zone, the dominant form of gas release would be from diffusion.

In an underground rock salt excavation, fracturing is observable and well defined in relation to a mined room. Fracturing is ever present at a short distance (a few meters) into a wall, floor, or roof of an opening. The fractures begin to form as the opening is approached by mining as the stress in the rock is relieved. Our laboratory work suggests that noble gas release may be used in conjunction with observation, displacement measurements, and model predictions as a deformation signal in an underground rock salt excavation with a controlled/monitored ventilation system (i.e., a nuclear waste repository). A lithology would first be characterized for its geogenic gas release signature as a function of deformation. Deformation events would need to damage sufficient rock in an amount of time for a puff of gas to be generated and sensed above the background. Field measurements may be accomplished using continuous or small interval sampling methods accessing the mine exhaust; thus, this technology could be used to "signal" unplanned events, like a roof collapse.

The real-time measurements of noble gas release during triaxial deformation of bedded rock salt were built in our previous work by exploring the gas release versus deformation in a situation conducive to fracture and situations in which fracture is inhibited by pressure. The noble gas release pattern we observed is consistent with our previous work with granite [3]. Similarly, radon emission has been detected in laboratory experiments during deformation $[5,6,20,36])$. The methods deployed herein, sensing helium and argon, achieve significantly better temporal resolution.

We tested samples first at greater pressure when microfracturing was suppressed (small amount of acoustic emissions), followed by lower-pressure testing wherein microfracturing was more evident (more acoustic emissions). Sample reuse in rock salt has been used by others to elucidate relationships between microfracturing and 
mechanical and transport properties (i.e., [24]). Here, the reuse demonstrates that microfracturing is necessary to release measurable amounts of noble gas.

For low confining pressure brittle conditions, the noble gas release signal begins early in the loading and continues during axial loading. During compaction, early in the deformation, cracks are formed (acoustic emissions are sensed) and noble gases are released at increasing amounts. Because helium flow rate increases in advance of the transition from compaction to dilation, we conclude that helium release may represent a highly sensitive sensor of microcracking. Previous work shows that gas release is a sensitive precursor to macrofracture [3]. No macrofracture was observed in these tests because these tests were of small axial strain $(<0.025$ axial), too small for a macrofracture to develop in rock salt as rock salt is prone to macrofracture only under very low confining pressure, lower than those explored in this study.

It is our assumption that each sample contained roughly the same amount of noble gases at the start of experimentation and that the amount of gas is related to the volume of pores and pore structure associated with water/brine residing in fluid inclusions and along grain boundaries. There is likely water/brine bound in the clays, polyhalite, and gypsum (samples were $<2 \%$ insoluble minerals). The release of noble gases associated with deformation of this small volume fraction of the rock is unknown. The evolution of the pore structure of rock salt during deformation is surmised by acoustic emissions and noble gas release. The increase in acoustic emissions with strain at a given confining pressure implies that cracks are forming continuously, increasing in number and likely interacting. If the cracks are interconnected through the sample, permeability should be increasing with increasing axial deformation. For successive tests at decreasing confining pressure, the increase in acoustic emissions and cumulative noble gas released similarly implies increasing crack numbers and more pore connection. At greater pressure, microfracturing is inhibited in halite, as the crystals deform by crystal plastic mechanisms. The empirical relationships between gas release and acoustic emissions suggest that the two deformation sensors provide complimentary information to quantify rock deformation.

The observations of inter- and intracrystalline sites before and after deformation shed light on the source of noble gases measured during deformation. Undeformed salt shows visible sources of trapped gas and liquid. We observed that intragranular sites (fluid inclusions) as well as tubules along grain boundaries are accessed by microfractures. These reservoirs likely represent a significant source of the noble gases detected.

This work provides additional laboratory data sets to support potential field monitoring of the release of naturally occurring ${ }^{4} \mathrm{He},{ }^{40} \mathrm{Ar}$, and other noble gases in the subsurface to monitor changes in stress, strain, and permeability in the subsurface for applications including earthquake prediction, volcanic activity, mining integrity, and nuclear waste disposal. The coupling of a detailed observation of operative processes at each step of the deformation, using for example acoustic emissions and strain, provides insight into the relationship between gas release and deformation of the rock. A quantitative interpretation of experiments of this kind is to be used for developing constitutive relationships between mechanical deformation, gas release, and permeability and the ability to use naturally occurring as well as doped tracers to observe and monitor mechanical deformation.

\section{Data Availability}

The data used to support the findings of this study are available from the corresponding author upon request.

\section{Conflicts of Interest}

The authors declare that they have no conflicts of interest.

\section{Acknowledgments}

Sandia National Laboratories is a multimission laboratory managed and operated by National Technology and Engineering Solutions of Sandia, LLC, a wholly owned subsidiary of Honeywell International Inc., for the U.S. Department of Energy's National Nuclear Security Administration under contract DE-NA0003525. This was supported by the Sandia National Laboratories Laboratory Directed Research and Development program.

\section{References}

[1] T. Torgersen, "Controls on porefluid concentration of ${ }^{4} \mathrm{He}$ and ${ }^{222} \mathrm{Rn}$ and the calculation of ${ }^{4} \mathrm{He} /{ }^{222} \mathrm{Rn}$ ages," Journal of Geochemical Exploration, vol. 13, no. 1, pp. 57-75, 1980.

[2] S. J. Bauer, W. P. Gardner, and J. E. Heath, "Helium release during shale deformation: experimental validation," Geochemistry, Geophysics, Geosystems, vol. 17, no. 7, pp. 2612-2622, 2016.

[3] S. J. Bauer, W. P. Gardner, and H. Lee, "Release of radiogenic noble gases as a new signal of rock deformation," Geophysical Research Letters, vol. 43, no. 20, pp. 10,688-10,694, 2016.

[4] K. Koike, T. Yoshinaga, K. Suetsugu, K. Kashiwaya, and H. Asaue, "Controls on radon emission from granite as evidenced by compression testing to failure," Geophysical Journal International, vol. 203, no. 1, pp. 428-436, 2015.

[5] A. Nicolas, F. Girault, A. Schubnel et al., "Radon emanation from brittle fracturing in granites under upper crustal conditions," Geophysical Research Letters, vol. 41, no. 15, pp. 5436-5443, 2014.

[6] P. Tuccimei, S. Mollo, S. Vinciguerra, M. Castelluccio, and M. Soligo, "Radon and thoron emission from lithophysaerich tuff under increasing deformation: an experimental study," Geophysical Research Letters, vol. 37, no. 5, 2010.

[7] B. M. Kennedy and M. C. van Soest, "Flow of mantle fluids through the ductile lower crust: helium isotope trends," Science, vol. 318, no. 5855, pp. 1433-1436, 2007.

[8] B. M. Kennedy, Y. K. Kharaka, W. C. Evans et al., "Mantle fluids in the San Andreas fault system, California," Science, vol. 278, no. 5341, pp. 1278-1281, 1997.

[9] W. P. Gardner, G. A. Harrington, and B. D. Smerdon, "Using excess ${ }^{4} \mathrm{He}$ to quantify variability in aquitard leakage," Journal of Hydrology, vol. 468-469, pp. 63-75, 2012. 
[10] F. Girault, F. Perrier, R. Crockett et al., "The Syabru-Bensi hydrothermal system in central Nepal: 1. Characterization of carbon dioxide and radon fluxes," Journal of Geophysical Research: Solid Earth, vol. 119, no. 5, pp. 4017-4055, 2014.

[11] C. R. Carrigan and Y. Sun, "Detection of noble gas radionuclides from an underground nuclear explosion during a CTBT on-site inspection," Pure and Applied Geophysics, vol. 171, no. 3-5, pp. 717-734, 2014.

[12] A. A. Giardini, G. V. Subbarayudu, and C. E. Melton, "The emission of occluded gas from rocks as a function of stress: its possible use as a tool for predicting earthquakes," Geophysical Research Letters, vol. 3, no. 6, pp. 355-358, 1976.

[13] G. Immè and D. Morelli, "Radon as earthquake precursor in earthquake research and analysis - statistical studies," in Observations and Planning, S. D'Amico, Ed., p. 460, In Tech pub, 2012.

[14] G. Igarashi, S. Saeki, N. Takahata et al., "Ground-water radon anomaly before the Kobe earthquake in Japan," Science, vol. 269 , no. 5220 , pp. 60-61, 1995.

[15] T. F. Yang, V. Walia, L. L. Chyi et al., "Variations of soil radon and thoron concentrations in a fault zone and prospective earthquakes in SW Taiwan," Radiation Measurements, vol. 40, no. 2-6, pp. 496-502, 2005.

[16] K. Bräuer, H. Kämpf, G. Strauch, and S. M. Weise, "Isotopic evidence $\left({ }^{3} \mathrm{He} /{ }^{4} \mathrm{He},{ }^{13} \mathrm{CCO} 2\right)$ of fluid-triggered intraplate seismicity," Journal of Geophysical Research: Solid Earth, vol. 108, no. B2, 2003.

[17] E. Padrón, N. M. Pérez, P. A. Hernández et al., "Diffusive helium emissions as a precursory sign of volcanic unrest," GEOLOGY, vol. 41, no. 5, pp. 539-542, 2013.

[18] J. B. Lowenstern, W. C. Evans, D. Bergfeld, and A. G. Hunt, "Prodigious degassing of a billion years of accumulated radiogenic helium at Yellowstone," Nature, vol. 506, no. 7488, pp. 355-358, 2014.

[19] M. Honda, K. Kurita, Y. Hamano, and M. Ozima, "Experimental studies of He and Ar degassing during rock fracturing," Earth and Planetary Science Letters, vol. 59, no. 2, pp. 429436, 1982.

[20] S. Mollo, P. Tuccimei, M. J. Heap et al., "Increase in radon emission due to rock failure: an experimental study," Geophysical Research Letters, vol. 38, no. 14, 2011.

[21] N. L. Carter and F. D. Hansen, "Creep of rocksalt," Tectonophysics, vol. 92, no. 4, pp. 275-333, 1983.

[22] N. L. Carter, S. T. Horseman, J. E. Russell, and J. Handin, "Rheology of rocksalt," Journal of Structural Geology, vol. 15, no. 910, pp. 1257-1271, 1993.

[23] A. F. Fossum and J. T. Fredrich, "Salt mechanics primer for near-salt and sub-salt deepwater Gulf of Mexico field developments SAND2002-2063," Sandia National Laboratories, 2002.

[24] T. Popp and H. Kern, "Monitoring the state of microfracturing in rock salt during deformation by combined measurements of permeability and P- and S- wave velocities," Physics and Chemistry of the Earth, Part A: Solid Earth and Geodesy, vol. 25, no. 2, pp. 149-154, 2000.

[25] S. J. Lambert, "Geochemistry of the waste isolation pilot plant (WIPP) site, southestern New Mexico, U.S.A..," Applied Geochemistry, vol. 7, no. 6, pp. 513-531, 1992.

[26] C. L. Stein and J. L. Krumhansl, "A model for the evolution of brines in salt from the lower Salado Formation, southeastern New Mexico," Geochimica et Cosmochimica Acta, vol. 52, no. 5, pp. 1037-1046, 1988.
[27] S. J. Bauer and A. Urquhart, "Thermal and physical properties of reconsolidated crushed rock salt as a function of porosity and temperature," Acta Geotechnica, vol. 11, no. 4, pp. 913924, 2016.

[28] R. M. Roberts, R. L. Beauheim, and P. S. Domski, Hydraulic Testing of Salado Formation Evaporites at the Waste Isolation Pilot Plant Site: Final Report, SAND98-2537, Sandia National Laboratories, Albuquerque, NM, 1999.

[29] S. J. Bauer, B. Song, and B. Sanborn, "Dynamic compressive strength of rock salts," International Journal of Rock Mechan$i c s$ and Mining Sciences, vol. 113, pp. 112-120, 2019.

[30] M. Friedman, W. F. Dula, A. F. Gangi, and G. A. Gazonas, "Structural petrology of experimentally deformed synthetic rocksalt," Proceedings of the First Conference on the Mechanical Behavior of Salt held at the Pennsylvania State University, Clausthal-Zellerfeld, Trans Tech Publications, University Park, 1981.

[31] W. Liang, C. Zhang, H. Gao, X. Yang, S. Xu, and Y. Zhao, "Experiments on mechanical properties of salt rocks under cyclic loading," Journal of Rock Mechanics and Geotechnical Engineering, vol. 4, no. 1, pp. 54-61, 2012.

[32] W. Yang, R. P. Gamage, C. Huang, G. Luo, J. Guo, and S. Wang, "Loading history effect on creep deformation of rock," Energies, vol. 11, no. 6, p. 1462, 2018.

[33] G. Wang, L. Zhang, Y. Zhang, and G. Ding, "Experimental investigations of the creep-damage-rupture behaviour of rock salt," International Journal of Rock Mechanics and Mining Sciences, vol. 66, pp. 181-187, 2014.

[34] S. J. Bauer, "Observation of the Kaiser effect using noble gas release signals," Rock Mechanics and Rock Engineering, vol. 51, no. 2, pp. 647-651, 2018.

[35] W. P. Gardner, S. J. Bauer, K. L. Kuhlman, and J. E. Heath, "Modeling dynamic helium release as a tracer of rock deformation," Journal of Geophysical Research: Solid Earth, vol. 122, no. 11, pp. 8828-8838, 2017.

[36] R. F. Holub and B. T. Brady, "The effect of stress on radon emanation from rock," Journal of Geophysical Research, vol. 86, no. NB3, pp. 1776-1784, 1981. 

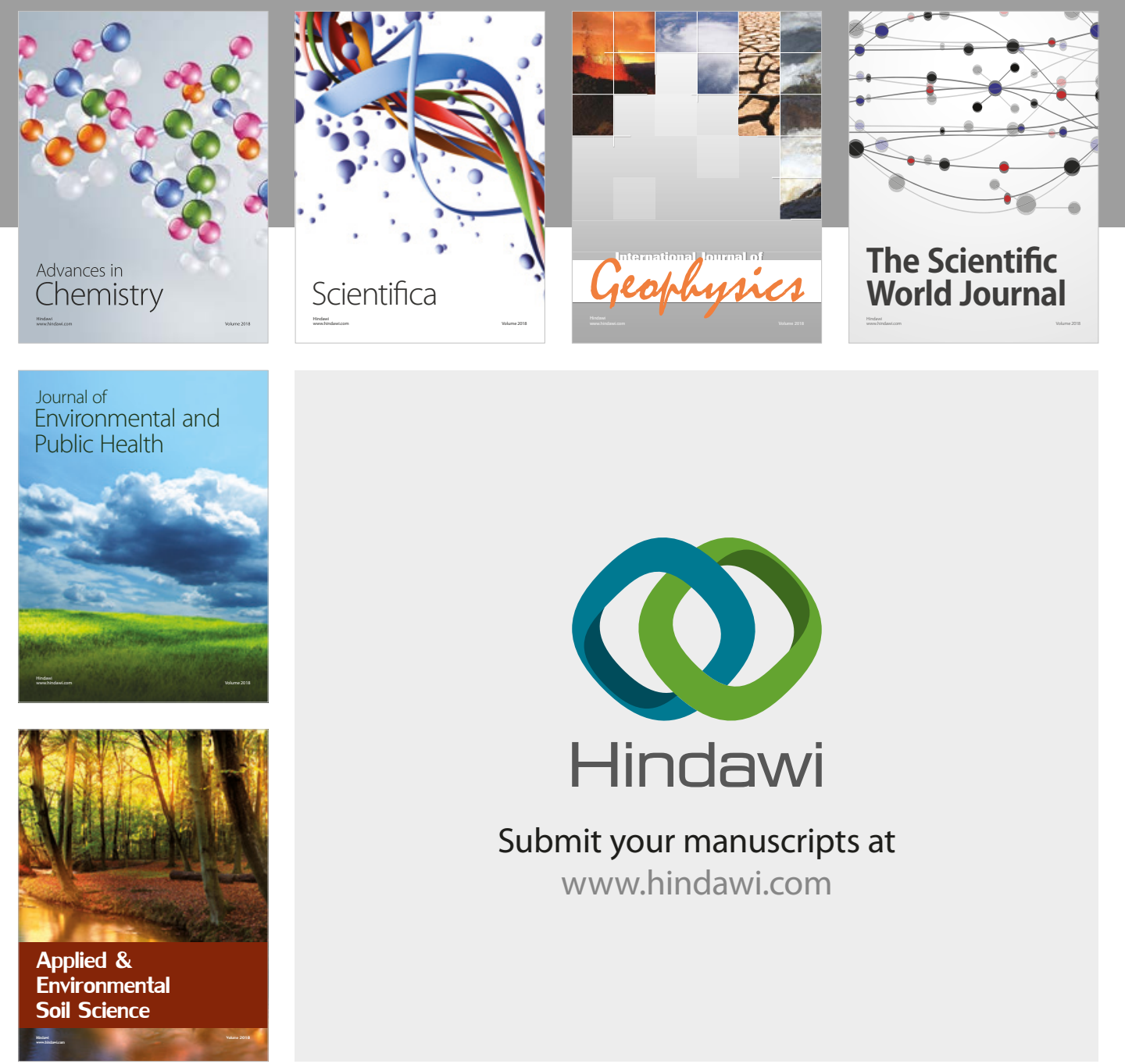

The Scientific

\section{World Journal}
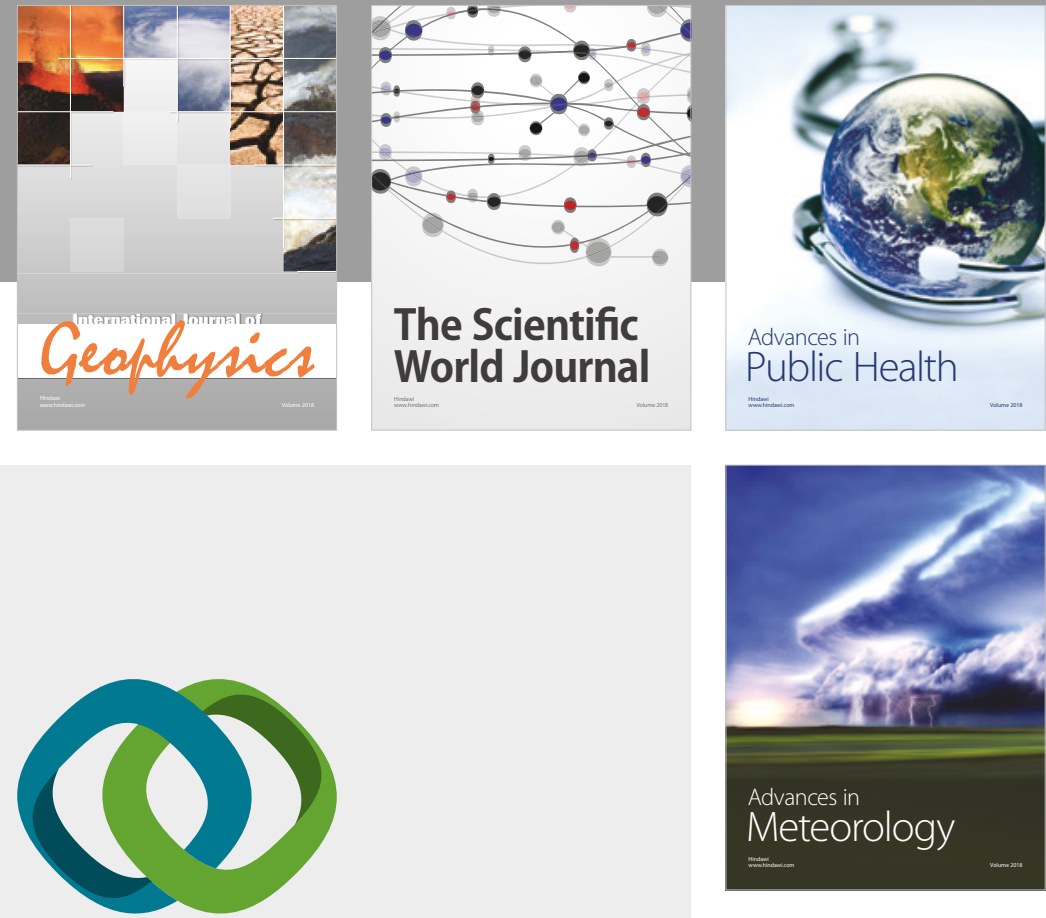

Advan

Public Health

\section{Hindawi}

Submit your manuscripts at

www.hindawi.com
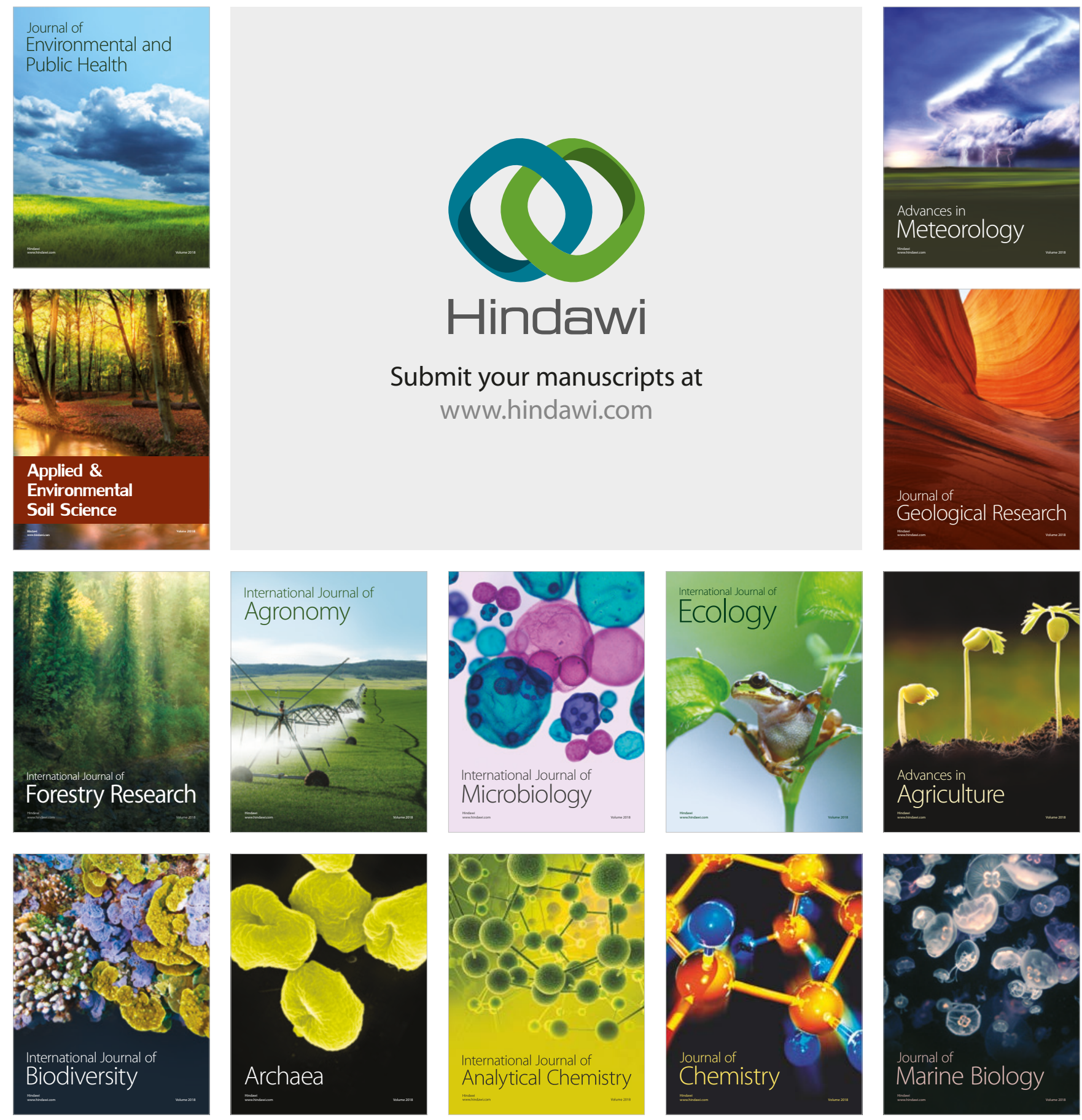